\title{
Differential expression and release of exosomal miRNAs by human islets under inflammatory and hypoxic stress
}

\author{
Prathab Balaji Saravanan ${ }^{1} \cdot$ Srividya Vasu ${ }^{2} \cdot$ Gumpei Yoshimatsu ${ }^{2} \cdot$ Carly M. Darden ${ }^{2} \cdot$ Xuan Wang ${ }^{2} \cdot$ Jinghua Gu $^{2}$. \\ Michael C. Lawrence ${ }^{2}$ (D) Bashoo Naziruddin $^{3}$ (D)
}

Received: 11 February 2019 / Accepted: 29 May 2019 / Published online: 1 August 2019

(C) Springer-Verlag GmbH Germany, part of Springer Nature 2019

\begin{abstract}
Aims/hypothesis Pancreatic islets produce non-coding microRNAs (miRNAs) that regulate islet cell function and survival. Our earlier investigations revealed that human islets undergo significant damage due to various types of stresses following transplantation and release miRNAs. Here, we sought to identify and validate exosomal miRNAs (exo-miRNAs) produced by human islets under conditions of cellular stress, preceding loss of cell function and death. We also aimed to identify islet stress signalling pathways targeted by exo-miRNAs to elucidate potential regulatory roles in islet cell stress.

Methods Human islets were subjected to proinflammatory cytokine and hypoxic cell stress and miRNA from exosomes was isolated for RNA sequencing and analysis. Stress-induced exo-miRNAs were evaluated for kinetics of expression and release by intact islets for up to $48 \mathrm{~h}$ exposure to cytokines and hypoxia. A subset of stress-induced exo-miRNAs were assessed for recovery and detection as biomarkers of islet cell stress in a diabetic nude mouse xenotransplant model and in patients undergoing total pancreatectomy with islet auto-transplantation (TPIAT). Genes and signalling pathways targeted by stress-induced exo-miRNAs were identified by Kyoto Encyclopedia of Genes and Genomes (KEGG) analysis and direct interactions of miRNAs with downstream signalling targets were validated in human islet cells using the miRNA Tests for Read Analysis and Prediction (MirTrap) system.

Results Global exo-miRNA sequencing revealed that 879 miRNA species were released from human islets and 190 islet exomiRNAs were differentially expressed in response to proinflammatory cytokines, hypoxia or both. Release of exo-miRNAs hsamiR-29b-3p and hsa-miR-216a-5p was detected within $6 \mathrm{~h}$ of exposure to cytokines and hypoxia. The remaining subset of stressinduced exo-miRNAs, including hsa-miR-148a-3p and islet cell damage marker hsa-miR-375, showed delayed release at 24 $48 \mathrm{~h}$, correlating with apoptosis and cell death. Stress and damage exo-miRNAs were significantly elevated in the circulation in human-to-mouse xenotransplant models and in human transplant recipients. Elevated blood exo-miRNAs negatively correlated with post-transplant islet function based on comparisons of stress and damage exo-miRNA indices with Secretory Unit of Islet Transplant Objects (SUITO) indices. KEGG analysis and further validation of exo-miRNA targets by MirTrap analysis revealed significant enrichment of islet mRNAs involved in phosphoinositide 3-kinase/Akt and mitogen-activated protein kinase signalling pathways.

Conclusions/interpretation The study identifies exo-miRNAs differentially expressed and released by islets in response to damage and stress. These exo-miRNAs could serve as potential biomarkers for assessing islet damage and predicting outcomes in islet transplantation. Notably, exo-miRNAs 29b-3p and 216a-5p could be detected in islets prior to damage-released miRNAs and indicators of cellular apoptosis and death. Thus, these stress-induced exo-miRNAs may have potential diagnostic value for
\end{abstract}

Electronic supplementary material The online version of this article (https://doi.org/10.1007/s00125-019-4950-x) contains peer-reviewed but unedited supplementary material, which is available to authorised users.

Michael C. Lawrence

Michael.Lawrence@BSWHealth.org

Bashoo Naziruddin

Bashoo.Naziruddin@BSWHealth.org

1 Division of Transplantation, Department of Surgery, Virginia Commonwealth University, Medical Center, Richmond, VA, USA
2 Islet Cell Laboratory, Baylor Scott and White Research Institute, 3434 Live Oak Street, Dallas, TX 75204, USA

3 Islet Cell Laboratory, Baylor Simmons Transplant Institute, 3410 Worth Street, Suite 950, Dallas, TX 75246, USA 


\section{Research in context}

\section{What is already known about this subject?}

- Currently known non-invasive biomarkers of islet beta cell dysfunction, including circulating proinsulin, C-peptide, glucose tolerance tests, SUITO index and $\mathrm{HbA}_{1 \mathrm{c}}$, do not accurately detect beta cell stress in the prediabetic state or post islet transplantation

- Beta cell-specific miRNA 375 can be used to detect beta cell damage and loss of islet cell mass

- Exosomal miRNAs (exo-miRNAs) play a role in cell communication and adaptation and can be recovered and detected in the circulation at relatively low concentrations

\section{What is the key question?}

- What exo-miRNAs are produced by human islets during stress conditions before loss of function and cell death?

\section{What are the new findings?}

- One hundred and ninety islet exo-miRNAs are differentially expressed and released in response to proinflammatory cytokines and hypoxic stress

- A subset of exo-miRNAs is released by islets in a stress-specific manner and may provide molecular signatures that can be used as diagnostic biomarkers of islet cell stress preceding islet cell damage and loss of islet function

- $\quad$ Stress-induced islet exo-miRNAs target genes in the PI3K/Akt and mitogen-activated protein kinase (MAPK) signalling pathways

How might this impact on clinical practice in the foreseeable future?

- Stress-selective exo-miRNAs may have potential use as diagnostic biomarkers of islet cell stress in a prediabetic state to allow therapeutic interventions prior to loss of islet cell mass and function

detecting early islet stress prior to progressive loss of islet cell mass and function. Further investigations are warranted to investigate the utility of these exo-miRNAs as early indicators of islet cell stress during prediabetic conditions.

Keywords Cellular stress $\cdot$ Exosomal miRNA $\cdot$ Islet cell damage $\cdot$ Islet transplantation $\cdot$ PI3K-Akt signalling pathway

$\begin{array}{ll}\text { Abbreviations } & \\ \text { BAD } & \text { BCL2-associated death promoter } \\ \text { Casp-3 } & \text { Caspase-3 } \\ \text { CC } & \text { Cytokine cocktail } \\ \text { c-Casp-3 } & \text { Cleaved Casp-3 } \\ \text { CHOP } & \begin{array}{l}\text { CCAAT-enhancer-binding protein homolo- } \\ \text { gous protein }\end{array} \\ \text { DMI } & \text { Damage miRNA index } \\ \text { D-miR } & \text { Damaged-induced exo-miRNA } \\ \text { ER } & \text { Endoplasmic reticulum } \\ \text { exo-miRNA } & \text { Exosomal miRNA } \\ \text { FDA } & \text { Fluorescein diacetate } \\ \text { FOXO1 } & \text { Forkhead box protein O1 } \\ \text { HIF-1 } \alpha & \text { Hypoxia inducible factor 1 } \alpha \\ \text { Hsp70 } & \text { Heat-shock protein 70 } \\ \text { HYP } & \text { Hypoxia (experimental treatment) } \\ \text { IEQ } & \text { Islet equivalent } \\ \text { IRE } & \text { Inositol-requiring enzyme } \\ \text { KEGG } & \text { Kyoto Encyclopedia of Genes and Genomes } \\ \text { miRNA } & \text { MicroRNA } \\ \text { MirTrap } & \text { miRNATests for Read Analysis and Prediction }\end{array}$

mTOR Mammalian target of rapamycin

NTA Nanoparticle tracking analysis

PI Propidium iodide

PI3K Phosphoinositide 3-kinase

qPCR Quantitative PCR

SMI Stress miRNA index

S-miR Stress-induced exo-miRNA

STZ Streptozotocin

SUITO Secretory Unit of Islet Transplant Objects

TEM Transmission electron microscopy

TPIAT Total pancreatectomy with islet

XBP1 X-box binding protein 1 isoform

\section{Introduction}

Pancreatic islets express inflammatory mediators such as chemokine (C-C motif) ligand 2 (CCL2), C-X-C motif chemokine 10 (CXCL10), IL-1 $\beta$, TNF- $\alpha$ and IL-6 in response to 
metabolic, inflammatory, oxidative and hypoxic stress signals to adapt, repair or restore islet function [1-5]. These inflammatory mediators have been observed in islets under conditions of type 1 and type 2 diabetes as well as during islet transplantation $[1,2,6]$. Currently known noninvasive biomarkers of islet beta cell dysfunction include circulating proinsulin, C-peptide, glucose tolerance tests and $\mathrm{HbA}_{1 \mathrm{c}}$. However, these biomarkers are limited to detection of beta cell dysfunction at or after diagnosis of diabetes when islet cell function has already been significantly depleted. As yet, there are no reliable methods to detect islet cell stress during transplantation and in the prediabetic state prior to loss of islet cell mass and function. Thus, molecules specifically expressed in islets during cellular stress may qualify as stress-selective biomarkers to track the status of islets during prediabetic conditions. Such investigations would be useful for identifying timely interventions to preserve islet function after transplantation and in the prediabetic state.

Islet microRNAs (miRNAs) are known to play important roles in the regulation of islet function and survival [7-10]. Indeed, multiple miRNAs are associated with type 1 and 2 diabetes [11]. In islet transplantation, islets are subjected to stresses during procurement, isolation and engraftment. Upon transplantation, islets release miRNAs that are detected in the circulation $[12,13]$. These miRNA species are packed in exosomes that confer resistance to degradation. Exosomes, $\sim 100-200 \mathrm{~nm}$ in diameter, play important roles in cell communication and transfer of molecular species between cells. Thus, plasma-derived exosomal miRNAs (exo-miRNAs) are attractive candidates in the search for non-invasive biomarkers of islet cell stress and may enable tracking early progression of disease by stage-specific molecular signatures.

Several miRNAs correlate with islet damage and transplant outcomes. Notably, elevated hsa-miR-375 in the transplant medium and in sera of islet transplant recipients correlates with lower islet yield and poor transplant outcomes, respectively [12-14]. Elevated hsa-miR-200c is a predictive biomarker of endocrine outcome 1 year after islet autotransplantation [11]. Although hsa-miR-375 is a beta cellspecific biomarker that is sensitive and reliable for monitoring islet cell damage, it is limited to islets that have already been extensively damaged. In this study, we sought to identify and validate miRNAs induced in response to cellular stress before cells enter apoptosis using ex vivo studies and in vivo studies in mouse models of islet transplantation and during islet infusion in patients undergoing total pancreatectomy with islet auto-transplantation (TPIAT). Further analyses of downstream miRNA targets were performed and validated by Kyoto Encyclopedia of Genes and Genomes (KEGG) analysis and the miRNA Tests for Read Analysis and Prediction (MirTrap) system.

\section{Methods}

Human islets For ex vivo studies, human islets were procured from the Integrated Islet Distribution Program (City of Hope, Los Angeles, CA, USA). Blood samples were also tested from six patients admitted for TPIAT at Baylor University Medical Center. Islets were isolated from the pancreas (procured after total pancreatectomy) as described previously (see electronic supplementary material [ESM] Method 1) [12]. Islets were cultured in CMRL 1066 medium containing 10\% exosomedepleted FBS, $2 \mathrm{mmol} / \mathrm{l}$ glutamine, $100 \mathrm{U} / \mathrm{ml}$ penicillin and $100 \mu \mathrm{g} / \mathrm{ml}$ streptomycin at $37^{\circ} \mathrm{C}$ and $5 \% \mathrm{CO}_{2}$. For studies using cytokines and hypoxia, the islets were treated with proinflammatory cytokine cocktail (CC) containing IL- $1 \beta$ $(100 \mathrm{U} / \mathrm{ml})$, TNF- $\alpha(1000 \mathrm{U} / \mathrm{ml})$ and IFN- $\gamma(1000 \mathrm{U} / \mathrm{ml})$ and exposed to hypoxia (HYP; $1 \% \mathrm{O}_{2}, 5 \% \mathrm{CO}_{2}$ and $94 \%$ $\mathrm{N}_{2}$ ) for 6,12 and $24 \mathrm{~h}$ ex vivo. Viability of islets was determined using propidium iodide (PI)/fluorescein diacetate (FDA) staining. All human islet investigations were approved by the institutional review board.

Animal studies Male nude mice (NU/J-Foxn $1^{\text {nu }}$, The Jackson Laboratory, Sacramento, CA, USA) aged 8 weeks, $n=5$ in streptozotocin (STZ)-induced diabetic control, and kidney capsule and intraportal transplant groups, were housed individually with a $12 \mathrm{~h}$ dark-light cycle and fed standard rodent diet ad libitum. Mice were fasted overnight and dosed with STZ (160 mg/kg). Diabetes was established after two consecutive blood glucose measurements $>22.2 \mathrm{mmol} / 1$. Human islets $\left(2500\right.$ islet equivalents [IEQs], cultured routinely at $37^{\circ} \mathrm{C}$, with $5 \% \mathrm{CO}_{2}$ before transplantation) were transplanted under the kidney capsule or intraportally. Blood plasma samples were collected $24 \mathrm{~h}$ post transplantation and stored at $-80^{\circ} \mathrm{C}$ until further analyses. The human islet grafts were then resected from the kidney capsule for gene expression analyses using quantitative PCR (qPCR; see ESM Method 2). All animal procedures followed protocols of the institutional animal care and use committee.

Isolation and characterisation of exosomes Exosomes were isolated using the miRCURY exosome isolation kit (Exiqon, Woburn, MA, USA). Briefly, plasma or islet culture supernatant fraction was centrifuged at 10,000 or $3000 \mathrm{~g}$ for $5 \mathrm{~min}$ and exosomes were precipitated using precipitation buffer overnight at $4^{\circ} \mathrm{C}$, followed by centrifugation at $10,000 \mathrm{~g}$ at $20^{\circ} \mathrm{C}$. Transmission electron microscopy (TEM) and nanoparticle tracking analysis (NTA) analyses were performed to characterise exosomes (see ESM Method 3).

Exosomal miRNA transcriptome analysis Total RNA was extracted from exosomes using the miRCURY RNA isolation kit (Exiqon) following manufacturer's instructions. Exosomal miRNA (exo-miRNA) expression was analysed using LNA- 
based miRNA primers (Exiqon) and miRCURY Universal RT-PCR (Exiqon). For miRNA transcriptome analysis, a multiplex miRNA transcriptome library was constructed using a TruSeq RNA Library Prep Kit (Illumina, San Diego, CA, USA) (see ESM Method 4, 5).

Immunoblotting Expression of inositol-requiring enzyme (IRE-1 $\alpha$ ), X-box binding protein 1 isoform (XBP1), hypoxia inducible factor $1 \alpha(\mathrm{HIF}-1 \alpha)$, CCAAT-enhancer-binding protein homologous protein (CHOP), caspase-3 (Casp-3), cleaved Casp-3 (c-Casp-3), CD9 and $\beta$-actin in exosomes or islet extracts was determined using standard immunoblotting protocol (see ESM Method 6 for details of methods and antibodies).

Plasma exo-miRNA analyses during TPIAT During TPIAT, blood samples were collected $1 \mathrm{~h}$ before islet infusion, during islet infusion, upon completion of islet infusion and at $6 \mathrm{~h}$, 1 day and 7 days after completion of islet infusion. After transplantation, patients were followed up to 1 year to monitor islet graft function using $\mathrm{C}$-peptide, $\mathrm{HbA}_{1 \mathrm{c}}$ and Secretory Unit of Islet Transplant Objects (SUITO) index using established methods (see ESM Method 1).

KEGG analysis and MirTrap system In silico KEGG analysis was performed using DIANA tools mirPath (v.3, http://www. microrna.gr/miRPathv3) to predict the pathways influenced by stress/damage-specific miRNAs. The MirTrap system (Clontech, Mountain View, CA, USA) was used to identify specific miRNA targets and validate KEGG pathway prediction (see ESM Method 7 and Fig. 6b).

Statistical analysis Data were represented as mean $\pm \mathrm{SEM}$. Student's $t$ test was performed for statistical analysis or oneway ANOVA with Tukey-Kramer post hoc tests for analysis, wherever applicable. A $p$ value $<0.05$ was considered statistically significant. For correlation studies, Pearson's two-tailed correlation analysis was performed. Randomisation and blinding were not carried out for any analysis. All analyses were carried out using GraphPad Prism (version 7, GraphPad Software, San Diego, CA, USA).

\section{Results}

Induction of stress and apoptosis in human islets CC + HYP treatment increased the expression of HIF- $1 \alpha$, IRE- $1 \alpha$, XBP1 and CHOP within $6 \mathrm{~h}$ (Fig. $1 \mathrm{a}-\mathrm{e}, p<0.01$ to $p<0.001$ ). $\mathrm{CC}+$ HYP induced apoptotic marker c-Casp-3 within $24 \mathrm{~h}$ (Fig. $1 \mathrm{f}, \mathrm{g}, p<0.001)$. Casp-3 activation correlated with a progressive increase in $\mathrm{PI}^{+} / \mathrm{FDA}^{+}$cell frequency/IEQ from $12 \mathrm{~h}$ to $48 \mathrm{~h}$ (Fig. 1h,i, $p<0.001$ ). Thus, CC + HYP effects on islets progressed from activation of endoplasmic reticulum (ER) stress response within $6 \mathrm{~h}$ to apoptosis within $12 \mathrm{~h}$, to $>50 \%$ cell death by $24 \mathrm{~h}$.

Exosome characterisation and exo-miRNA sequencing analyses Approximately $0.8 \times 10^{7} / \mathrm{ml}$ exosomes per sample were recovered from human islets (2500 IEQ). TEM demonstrated round islet exosomes with cuplike concavity and a diameter of $\sim 100 \mathrm{~nm}$ (Fig. 2a-c). NTA confirmed a peak islet exosome size distribution of $\sim 110 \mathrm{~nm}$ (Fig. 2d). Islet exosomes expressed exosomal tetraspanin surface protein marker CD9 and heat-shock protein 70 (Hsp70) (Fig. 2d). Biospectral analysis confirmed that exosome RNAs were 18-23 nucleotides in length, with $>80 \%$ matches, consistent with average size of miRNAs (ESM Fig. 1a). CC and HYP treatments had a significant influence on miRNA expression in islet exosomes compared with control untreated islets and islets only treated with CC (ESM Fig. 1b).

RNA sequencing analysis revealed 879 exo-miRNA species released from human islets; 190 exo-miRNAs were differentially expressed in response to CC and/or HYP compared with control islets (Fig. 2e). Among this group, subgroups of 14, 52 and 33 exo-miRNAs were selectively expressed by human islets under conditions of stress (CC, HYP and $\mathrm{CC}+$ HYP, respectively, Fig. 2f).

Release of exo-miRNA from isolated human islets Of the 29 exo-miRNAs differentially expressed with statistical significance $(p<0.01$, except for hsa-miR-216a-5p and hsa-miR$200 c-3 p$ ), 11 were expressed under all stress conditions (Fig. 2f, Table 1). Eight of the 29 miRNA species (hsa-miR-375, $-216 a-5 p,-29 b-3 p,-148 a-3 p,-92 a-3 p,-200 c-3 p,-7-5 p$ and $-125 b-5 p$ ) were validated by qPCR to be differentially released in exosomes from human islets exposed to $\mathrm{CC}$ and/or HYP using commercially available primers (Exiqon; ESM Fig. 2).

Ex vivo time course analyses revealed distinction between early and late responses to CC + HYP, with release of exomiRNAs hsa-miR-29b-3p and hsa-miR-216a-5p within $6 \mathrm{~h}$ of CC + HYP exposure (Fig. 3a,b, $p<0.05$ to $p<0.001$ ). Other islet exo-miRNAs were not significantly expressed until $24-48$ h (Fig. $3 \mathrm{c}-\mathrm{h}, p<0.05$ to $p<0.001$ ). Release of exomiRNAs from stressed islets was suppressed up to $24 \mathrm{~h}$ by pre-treatment with GW4869, a neutral sphingomyelinase inhibitor that prevents ceramide-mediated maturation of exosomes. Collectively, these data indicate that hsa-miR$29 b-3 p$ and hsa-miR-216a-5p are selectively released in exosomes before apoptosis and cell death. Thus, we classify hsa-miR-29b-3p and hsa-miR-216a-5p as stress-induced exomiRNA (S-miR) and hsa-miR-375 and hsa-miR-148a-3p as damage-induced exo-miRNA (D-miR) miRNAs.

Exo-miRNA validation in vivo using human islets transplanted into nude mice To validate exo-miRNAs as biomarkers of islet cell stress, we used mouse models of human islet 


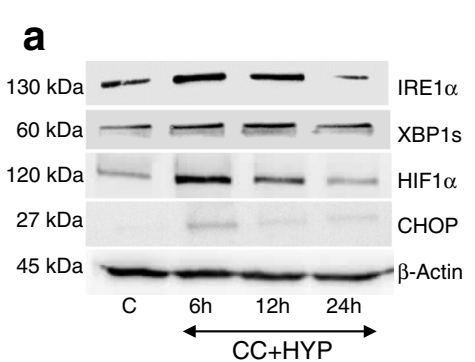

d

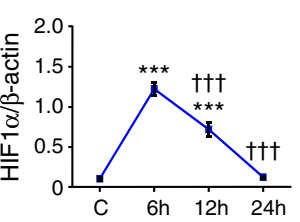

f

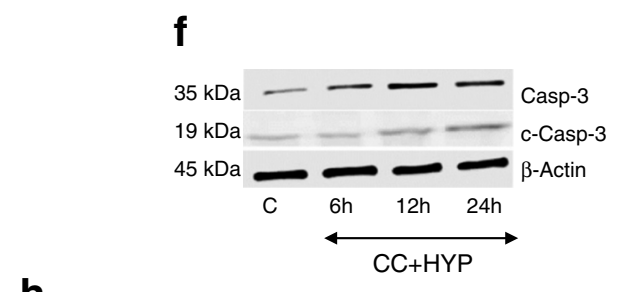

h

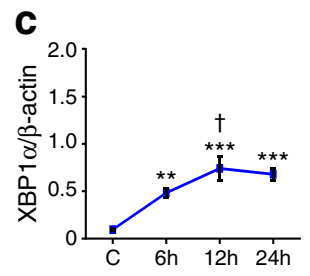

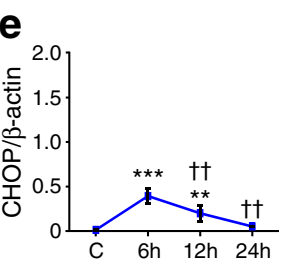
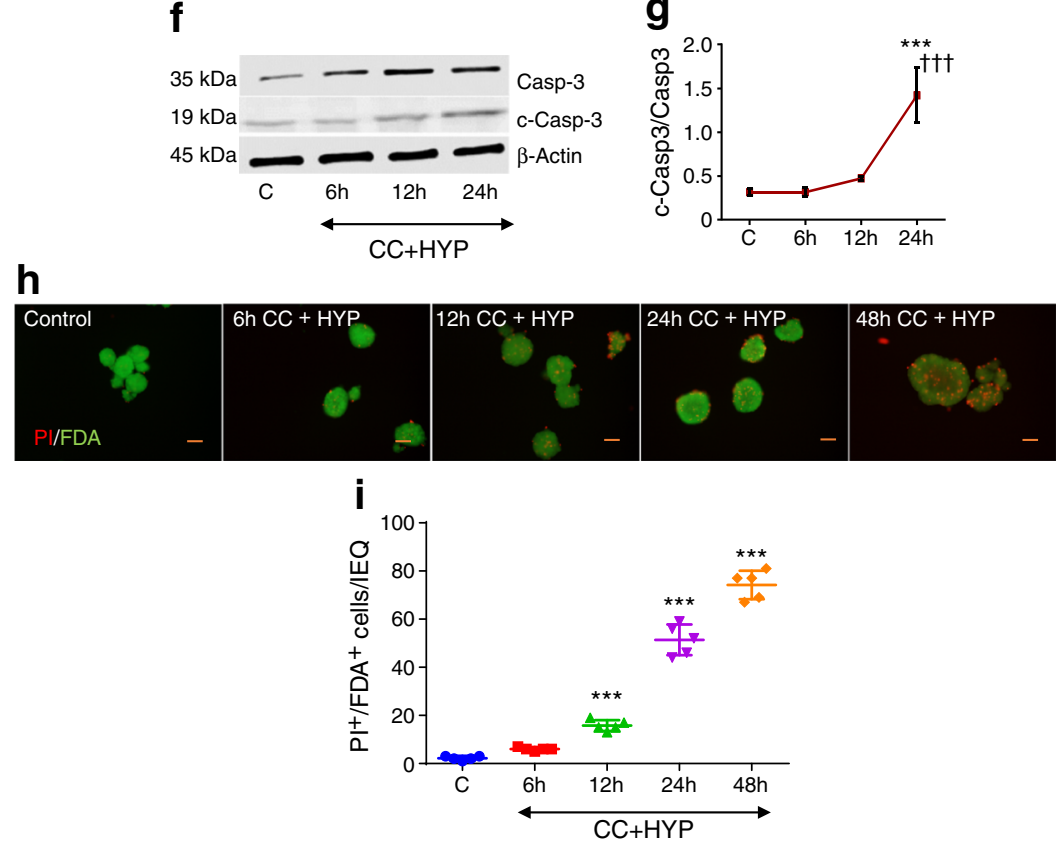

Fig. 1 Proinflammatory cytokines and hypoxia induce ER stress and apoptosis in human islets. Isolated human islets (1000 IEQs) were exposed to proinflammatory cytokines $(\mathrm{CC}$ : IL- $1 \beta[100 \mathrm{U} / \mathrm{ml}]+\mathrm{IFN}-\gamma$ $[1000 \mathrm{U} / \mathrm{ml}]+\mathrm{TNF}-\alpha[1000 \mathrm{U} / \mathrm{ml}])$ and hypoxia (HYP: $1 \% \mathrm{O}_{2}, 5 \%$ $\mathrm{CO}_{2}$ and $94 \% \mathrm{~N}_{2}$ ) for 6,12 and $24 \mathrm{~h}$ for immunoblotting, and for 6,12 , 24 and $48 \mathrm{~h}$ for PI/FDA staining. (a) Representative blots for expression of IRE- $1 \alpha$, XBP1, HIF- $1 \alpha$, CHOP and $\beta$-actin at the indicated time points. (b-e) Densitometry analysis, with protein expression normalised to $\beta$-actin. (f) Representative blots for expression of Casp-3, c-Casp-3, and $\beta$-actin at the indicated time points. (g) Densitometry analysis, with

transplantation. Diabetes was established in the mice $72 \mathrm{~h}$ after STZ administration. Human islets (2500 IEQs) were transplanted under the kidney capsule (Fig. 4a) or intraportally (ESM Fig. 3), and blood samples were collected $24 \mathrm{~h}$ postxenotransplantation. Human islet grafts decreased blood glucose levels $24 \mathrm{~h}$ after transplantation (Fig. $4 \mathrm{~b}$ and ESM Fig. 3a, $p<0.001$ ) but did not affect body weight (Fig. 4c and ESM Fig. 3b). Plasma exosomes at $24 \mathrm{~h}$ demonstrated similar size distributions and exosomal surface marker CD9 as observed in protein expression normalised to Casp-3. (h) Representative images showing PI/FDA-stained human islets. Scale bar, $100 \mu \mathrm{m}$. (i) Quantification of $\mathrm{PI}^{+} / \mathrm{FDA}^{+}$cells per IEQ at the indicated time points; approximately 20 IEQs were counted for analyses. Data are presented as mean \pm SEM ( $n=3$ samples). One-way ANOVA followed by Tukey's multiple comparison test was performed for statistical analyses. $* * * p<0.001$ compared with untreated control islets at $24 \mathrm{~h} ;{ }^{\dagger} p<0.05$, ${ }^{\dagger} p<0.01$ and ${ }^{\dagger \dagger} p<0.001$ compared with CC + HYP treatment at $6 \mathrm{~h}$. C denotes untreated control islets cultured routinely for $24 \mathrm{~h}$

ex vivo experiments (Fig. 4d). Both S-miR and D-miR were detected in plasma exosomes in the xenotransplantation groups but not in STZ diabetic mice (Fig. 4e-h, $p<0.001$ and ESM Fig. $3 c-$ g, $p<0.05, p<0.01)$. We normalised S-miRs and DmiRs to a stable exo-miRNA control, hsa-miR-889-3p (high baseMean $>500$, with no significant changes in expression over time ex vivo [ESM Fig. 2j] or after xenotransplantation [data not shown]), to provide basic quantifiable damage miRNA index (DMI) and stress miRNA index (SMI) (Fig. 4i). 

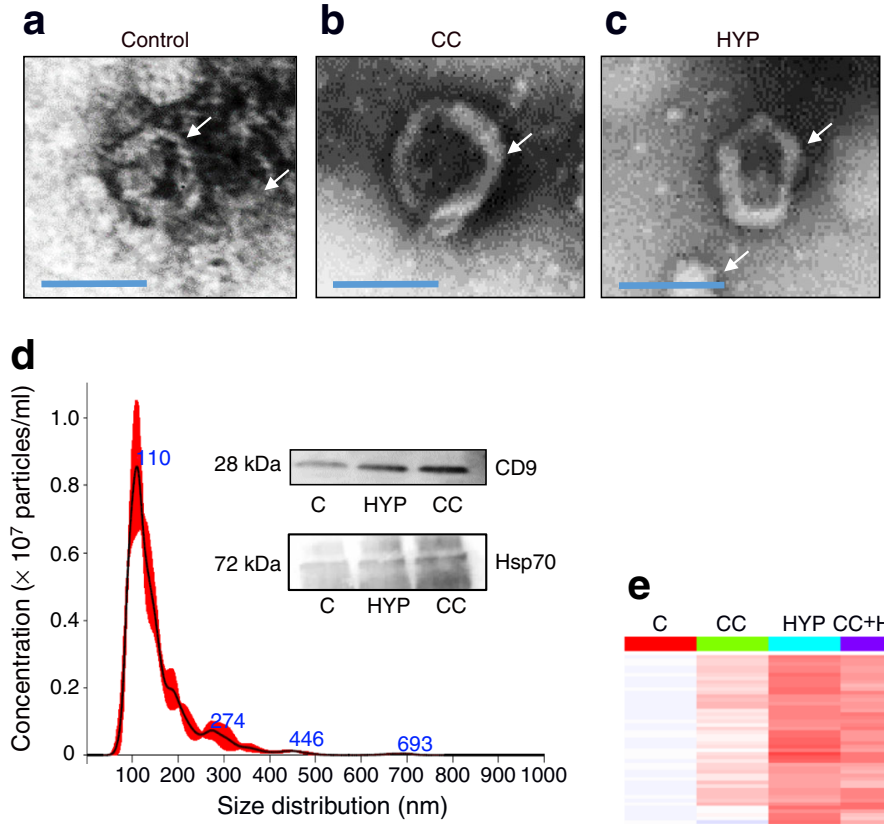

f
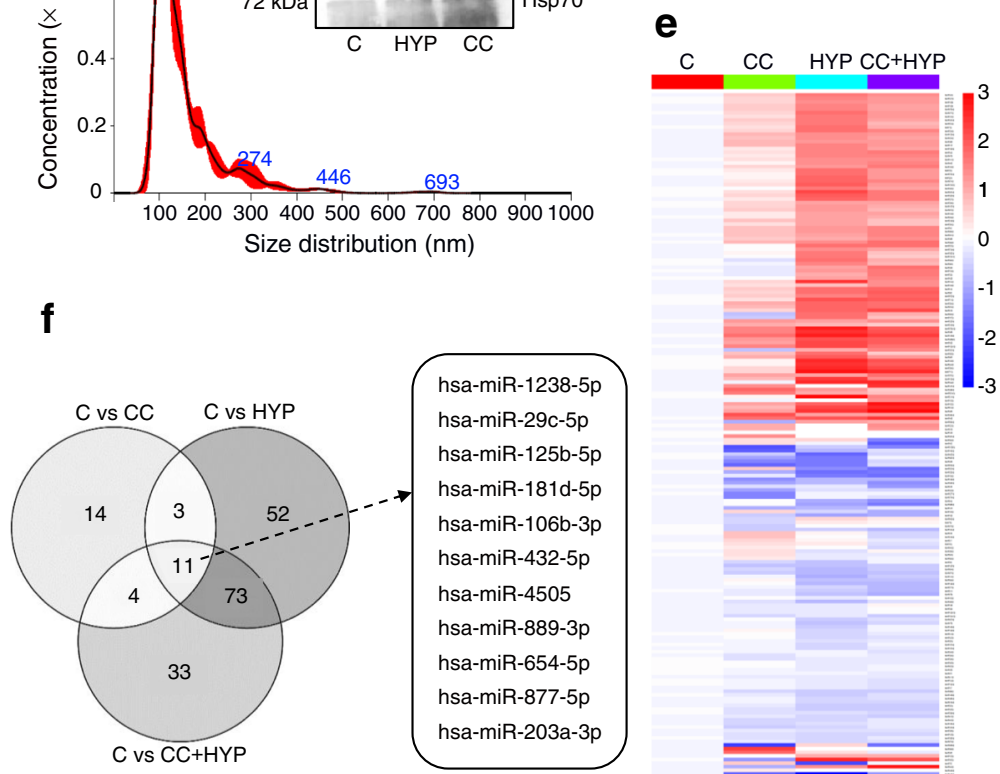

Fig. 2 Exosome characterisation and exo-miRNA sequencing analyses. $(\mathbf{a}-\mathbf{c})$ Representative TEM images of exosomes released from isolated human islets (2500 IEQ) exposed to CC (IL- $1 \beta[100 \mathrm{U} / \mathrm{ml}]+\mathrm{IFN}-\gamma$ $[1000 \mathrm{U} / \mathrm{ml}]+\mathrm{TNF}-\alpha[1000 \mathrm{U} / \mathrm{ml}])$ or $\mathrm{HYP}\left(1 \% \mathrm{O}_{2}, 5 \% \mathrm{CO}_{2}\right.$ and $94 \%$ $\mathrm{N}_{2}$ ) for $24 \mathrm{~h}$. Scale bar, $100 \mathrm{~nm}$. Arrows indicate exosomes. (d) Exosome size distribution (representative data showing control islet exosome distribution), estimated by the dynamic light scattering (DLS) method; inset shows exosomal CD9 and Hsp70 expression, assessed by western blot, from islets exposed to CC or HYP as detailed above. (e) Heat map representation of exo-miRNA sequencing data (differential expression analysis based on the negative binomial model) from islets exposed to CC, HYP or CC + HYP as detailed above. Colour codes for fold change are indicated in the heat map. (f) Venn diagram showing the number of differentially expressed exo-miRNAs released from human islets during exposure to CC, HYP and CC + HYP (limited to $p<0.05$ and fold change $>1.5$ vs control). Data are presented as mean \pm SEM ( $n=3$ samples). C denotes untreated control islets cultured routinely for $24 \mathrm{~h}$

provided in Table 2. Circulating levels of S-miR and D-miR increased significantly over time, peaking at completion of islet infusion (Fig. 5a, $p<0.05$ to $p<0.001$ ) and returned to normal at 7 days after islet infusion. Circulating levels of other exo-miRNAs (hsa-miR-200c-3p, -92a-3p, -125b-5p, -7f-5p and $-889-3 p$ ) did not change significantly over time (Fig. $5 b)$. At 1 year post transplantation, DMI $(r=-0.7961, p=$ $0.058)$ and SMI $(r=-0.8834, p=0.019)$ correlated negatively with SUITO index (Fig. 5c,f). DMI $(r=-0.3053, p=0.556)$ did not correlate with C-peptide (Fig. 5d), while SMI ( $r=$ $-0.6785, p=0.138$ ) correlated negatively with C-peptide albeit not significantly (Fig. 5g). DMI $(r=0.243, p=0.629)$ did not correlate with $\mathrm{HbA}_{1 \mathrm{c}}$ (Fig. 5e), while SMI $(r=0.7709, p=$ 
Table 1 Expression of 29 exo-miRNAs from sequence data with $p<0.05^{\mathrm{a}}$ or high baseMean

\begin{tabular}{|c|c|c|c|c|c|c|}
\hline No. & Transcript & baseMean & $\log _{2} \mathrm{FC}$ & $p$ value & FDR & Condition \\
\hline \multicolumn{7}{|c|}{ Exo-miRNAs expressed under all stress conditions } \\
\hline 1 & hsa-miR-1238-5p & 16.6 & 1.247 & 0.003 & 0.030 & All \\
\hline 2 & hsa-miR-29c-5p & 43.3 & 1.101 & 0.001 & 0.014 & All \\
\hline 3 & hsa-miR-125b-5p & 852.1 & 0.689 & 0.001 & 0.021 & All \\
\hline 4 & hsa-miR-181d-5p & 830.3 & -0.588 & 0.017 & 0.099 & All \\
\hline 5 & hsa-miR-106b-3p & 625.8 & -0.663 & 0.001 & 0.013 & All \\
\hline 6 & hsa-miR-432-5p & 12841.6 & -0.663 & 0.005 & 0.048 & All \\
\hline 7 & hsa-miR-4505 & 4.5 & -0.87 & 0.034 & NA & All \\
\hline 8 & hsa-miR-889-3p & 10255.3 & -0.953 & 0.0001 & 0.002 & All \\
\hline 9 & hsa-miR-654-5p & 270.7 & -0.985 & $<0.0001$ & 0.002 & All \\
\hline 10 & hsa-miR-877-5p & 620.6 & -1.030 & $<0.0001$ & $<0.001$ & All \\
\hline 11 & hsa-miR-203a-3p & 329.9 & -1.791 & $<0.0001$ & $<0.001$ & All \\
\hline \multicolumn{7}{|c|}{ Top exo-miRNAs with significant fold change ( $\left.\log _{2} \mathrm{FC}\right)$} \\
\hline 12 & hsa-miR-1200 & 16.7 & 1.715 & $<0.0001$ & 0.002 & $\mathrm{CC}+\mathrm{HYP}$ \\
\hline 13 & hsa-miR-29b-3p & 607.8 & 1.646 & $<0.0001$ & 0.0003 & $\mathrm{CC}+\mathrm{HYP}$ \\
\hline 14 & hsa-miR-185-5p & 64.0 & 1.420 & $<0.001$ & 0.008 & $\mathrm{CC}+\mathrm{HYP}$ \\
\hline 15 & hsa-miR-1251-5p & 33.1 & 1.417 & $<0.001$ & $<0.01$ & $\mathrm{CC}+\mathrm{HYP}$ \\
\hline 16 & hsa-miR-590-5p & 5.2 & 1.357 & $<0.001$ & NA & $\mathrm{CC}+\mathrm{HYP}$ \\
\hline 17 & hsa-miR-3613-3p & 14.2 & 1.279 & 0.003 & 0.035 & $\mathrm{CC}+\mathrm{HYP}$ \\
\hline 18 & hsa-miR-665 & 597.8 & 1.262 & $<0.0001$ & 0.0003 & $\mathrm{CC}+\mathrm{HYP}$ \\
\hline 19 & hsa-miR-7-5p & 592.4 & 1.223 & $<0.0001$ & $<0.001$ & $\mathrm{CC}+\mathrm{HYP}$ \\
\hline 20 & hsa-miR-320d & 1124.2 & 1.219 & $<0.0001$ & $<0.001$ & $\mathrm{CC}+\mathrm{HYP}$ \\
\hline \multicolumn{7}{|c|}{ Islet-specific exo-miRNAs with high baseMean (>550) } \\
\hline 21 & hsa-miR-375 & 1083171 & -0.610 & 0.01 & 0.082 & $\mathrm{CC}+\mathrm{HYP}$ \\
\hline 22 & hsa-miR-216a-5p & 554.169 & 0.352 & 0.075 & 0.255 & $\mathrm{CC}+\mathrm{HYP}$ \\
\hline 23 & hsa-miR-200c-3p & 820.160 & 0.403 & 0.095 & 0.288 & $\mathrm{CC}+\mathrm{HYP}$ \\
\hline 24 & hsa-miR-148a-3p & 397444.2 & -1.154 & $<0.0001$ & $<0.0001$ & $\mathrm{CC}+\mathrm{HYP}$ \\
\hline 25 & hsa-miR-92a-3p & 17655.06 & -1.148 & $<0.0001$ & $<0.0001$ & $\mathrm{CC}+\mathrm{HYP}$ \\
\hline 26 & hsa-miR-25-3p & 11817.34 & -0.931 & $<0.0001$ & $<0.001$ & $\mathrm{CC}+\mathrm{HYP}$ \\
\hline 27 & hsa-miR-409-3p & 22547.35 & -0.962 & $<0.0001$ & $<0.001$ & $\mathrm{CC}+\mathrm{HYP}$ \\
\hline 28 & hsa-miR-410-3p & 25901.78 & -0.914 & $<0.0001$ & $<0.001$ & $\mathrm{CC}+\mathrm{HYP}$ \\
\hline 29 & hsa-miR-129-5p & 12220.80 & -0.806 & $<0.001$ & $<0.01$ & $\mathrm{CC}+\mathrm{HYP}$ \\
\hline
\end{tabular}

${ }^{a}$ Except hsa-miR-216a-5p and hsa-miR-200c-3p

FC, fold change; FDR, false discovery rate

$0.069)$ correlated positively with $\mathrm{HbA}_{1 \mathrm{c}}$ albeit not significantly (Fig. 5h).

Exo-miRNA target analyses using the MirTrap system (hsamiR-29b-3p; hsa-miR-216a-5p) KEGG analysis revealed phosphoinositide 3-kinase (PI3K)-Akt, forkhead box protein $\mathrm{O} 1$ (FOXO1) and mammalian target of rapamycin (mTOR) signalling pathways, extracellular matrix-receptor interaction, biotin metabolism and platelet activation (Table 3, Fig. 6a) as targets of these exo-miRNAs. We validated exo-miRNAs (hsa-miR-216a-5p and hsa-miR-29b-3p) experimentally using the MirTrap system in dissociated human islet cells (Fig. 6b, ESM Method 7). Among 84 genes tested (PI3K-Akt signalling pathway $\mathrm{RT}^{2}$ profiler PCR array), 21 were significantly enriched after immunoprecipitation in dissociated human islet cells co-transfected with hsa-miR-29b-3p and hsa-miR-216a-5p mimics, and pMirTrap vector (Fig. $6 \mathrm{c}$, Table $4, p<0.05)$, confirmed by qPCR analyses $(15$ genes shown, Fig. 6d,e). Positive (Aequorea coerulescens GFP [AcGFP1]) and negative (procollagen-lysine, 2oxoglutarate 5-dioxygenase 3 [PLOD3]) controls for the experimental control transfection (hsa-miR-132 mimic, pMirTrap vector) validated the specificity of the MirTrap system (Fig. 6d, fold enrichment of AcGFP1 = 25.71, $p<0.001)$. Thus hsa-miR-29b-3p and hsa-miR-216a-5p interact with these signalling pathways in islets. 

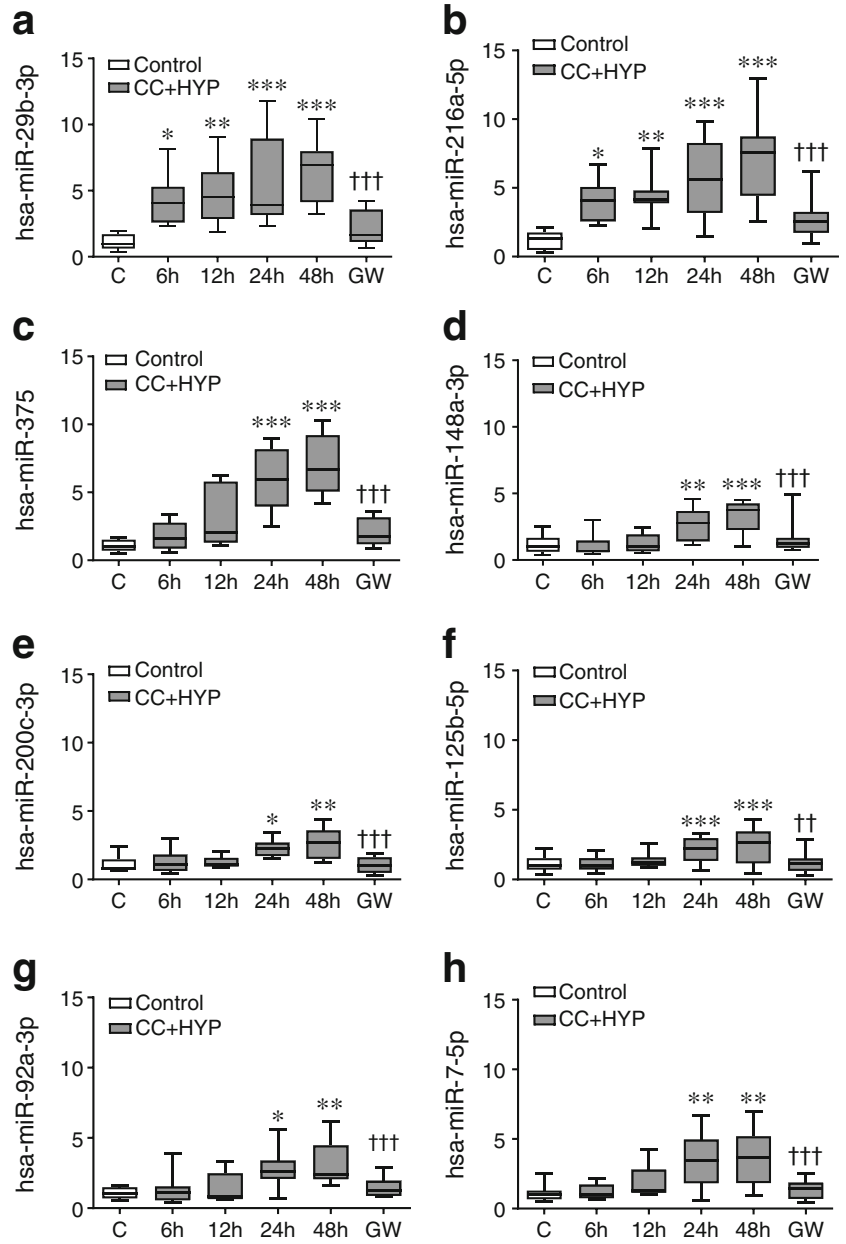

Fig. 3 Proinflammatory cytokines and hypoxia induce release of exosomes containing differentially expressed miRNAs from isolated human islets. Isolated human islets (2000 IEQ) were pre-treated for $2 \mathrm{~h}$ with or without the exosome inhibitor GW4869, and then exposed to CC+ HYP for the time points indicated in the figure. Exo-miRNA expression was determined using qPCR, normalised to U6 small RNA (spiked in) and plotted as fold change vs control. The following miRNA species were analysed: (a) hsa-miR-29b-3p; (b) hsa-miR-216a-5p; (c) hsa-miR-375; (d) hsa-miR-148a-3p; (e) hsa-miR-200c-3p; (f) hsa-miR-125b-5p; (g) hsa-miR-92a-3p; (h) hsa-miR-7-5p. Data are presented as mean \pm SEM ( $n=3$ samples). One-way ANOVA followed by Tukey's multiple comparison test was performed for statistical analyses. ${ }^{*} p<0.05, * * p<0.01$ and $* * * p<0.001$ compared with untreated control islets cultured routinely for $24 \mathrm{~h} ;{ }^{\dagger \dagger} p<0.01$ and ${ }^{\dagger \dagger} p<0.001$ compared with CC + HYP treatment at $24 \mathrm{~h}$. C denotes untreated control islets cultured routinely for $24 \mathrm{~h}$; GW, GW4869 (an inhibitor of exosome maturation)

\section{Discussion}

Using extensive ex vivo and in vivo mouse and human studies, we have validated two plasma exo-miRNAs, hsa-miR29b-3p and hsa-miR-216a-5p, specific for islet beta cell stress. In the context of islet transplantation, insulin independence depends on a number of factors including islet engraftment and function. Inflammation and hypoxia account for about $50 \%$ of islet cell death within $48-72 \mathrm{~h}$ of transplantation [15-20]. Furthermore, stress and damage during islet isolation and in the peri-transplant stages drastically influence the outcome of transplantation [12, 21-23]. Identification of specific circulating biomarkers of the early stages of beta cell stress, common to any islet microenvironments including prediabetes and transplantation, can improve treatment strategies.

Circulating or urinary miRNAs in microvesicles or exosomes are being evaluated as biomarkers of disease progression and diabetes complications [24-26]. Exosomal proteins and nucleic acids are resistant to degradation, as they are protected by a lipid bilayer. Their roles in cell communication, immune regulation, cell adhesion, tissue regeneration and elimination of harmful molecules are well established in multiple contexts [27-29]. Hence, exosome-based biomarkers are reliable and can be used to predict disease progression, predict treatment efficacy and aid in personalised medicine.

Upon exposure to CC + HYP, human islets released exosomes ( $\sim 110 \mathrm{~nm}$ in diameter), as reported earlier [30], with TEM analyses confirming the expected round-shaped morphology. Exosomes expressed CD9 and contained small RNA species (18-23 nucleotides). CC + HYP induced ER stress response within $6 \mathrm{~h}$ and apoptosis by $24 \mathrm{~h}$ [31-38]. The exo-miRNA sequencing analyses revealed that cytokines and/or hypoxia induced significant changes in exo-miRNA signature (ESM Fig. 1b). Our investigations included $>28,000$ miRNAs represented in the miRBase database ( $>80 \%$ sequence match). Diabetes environments, including glucotoxic and glucolipotoxic environments, influence alterations in islet miRNA transcription [39-42]. In rat islets, cytokines increased expression of islet miRNAs, including miR375 , miR-29b and miR-200c, after $6 \mathrm{~h}$ of exposure [43]. We identified 11 miRNAs that were differentially released in exosomes under all stress conditions. We selected the top nine exo-miRNAs with significant induction ( $\log _{2}$ fold change) and nine with high baseMean ( $>550)$ islet-specific exomiRNAs [10, 12, 13, 44-47] from our global miRNA sequencing (miRNA-seq) data for additional investigations.

Ex vivo qPCR analyses indicated that expression of eight exo-miRNAs was significantly increased after CC + HYP exposure. hsa-miR-29b-3p and hsa-miR-216a-5p were released in exosomes as early as $6 \mathrm{~h}$, coinciding with activation of ER stress response markers IRE- $1 \alpha$, XBP1, HIF- $1 \alpha$ and CHOP. Other miRNAs (hsa-miR-375, hsa-miR-148a-3p, hsa-miR200c-3p, hsa-miR-7-5p, hsa-miR-92a-3p and hsa-miR-125b$5 \mathrm{p}$ ) were released in exosomes at $24 \mathrm{~h}$, coinciding with Casp-3 activation, cell damage and induction of apoptosis (Fig. 1); GW4869 blocked their release, thus confirming the exosomal origin of these miRNAs. Thus, there is a clear demarcation between release of miRNAs in the early state of cellular stress and the state of cell damage and apoptosis. We classified these two categories of miRNAs as S-miR and D-miR, respectively. These early S-miRs are valuable and promising biomarkers of islet cell stress even before induction of cell damage and death. 
Fig. 4 Exo-miRNA validation in vivo using STZ diabetic nude mice. (a) Timeline of xenoislet transplantation under the kidney capsule of STZ diabetic nude mice. Blood glucose level (b) and body weight (c) of non-diabetic control, STZ diabetic and islettransplanted STZ diabetic mice. (d) Size distribution of plasma exosomes isolated from islettransplanted STZ diabetic mice, estimated by dynamic light scattering (DLS). Insets show TEM image of plasma exosome from an islet-transplanted STZ diabetic mouse (scale bar, $100 \mathrm{~nm}$ ) and blot showing exosomal CD9 expression (28 kDa). (e-h) Plasma exomiRNA expression. (i) DMI and SMI indices. Data are presented as mean $\pm \operatorname{SEM}(n=5$ mice). One-way ANOVA followed by Tukey's multiple comparison test was performed for statistical analyses. $* * * p<0.001$ compared with non-diabetic mice; ${ }^{\dagger} p<0.05$ and ${ }^{\dagger \dagger} p<0.001$ compared with STZ diabetic mice. BG, blood glucose; bw, body weight; ND, non-diabetic mice; TX, transplantation

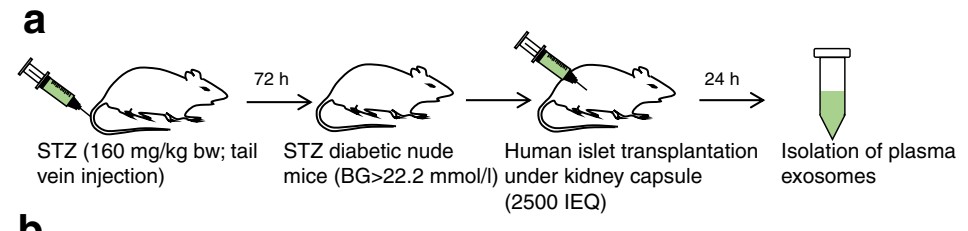

b
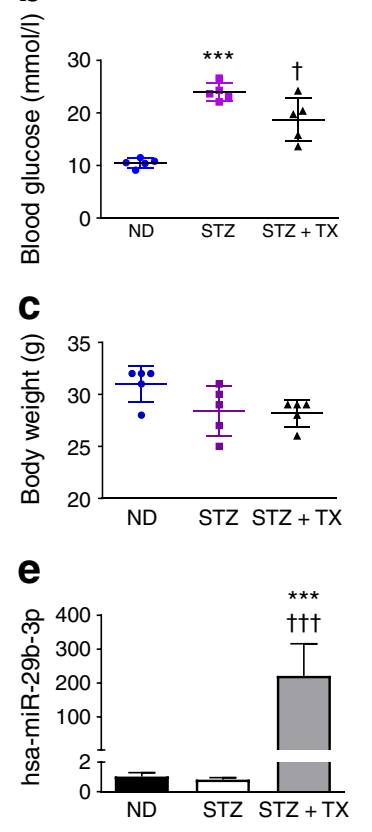

f
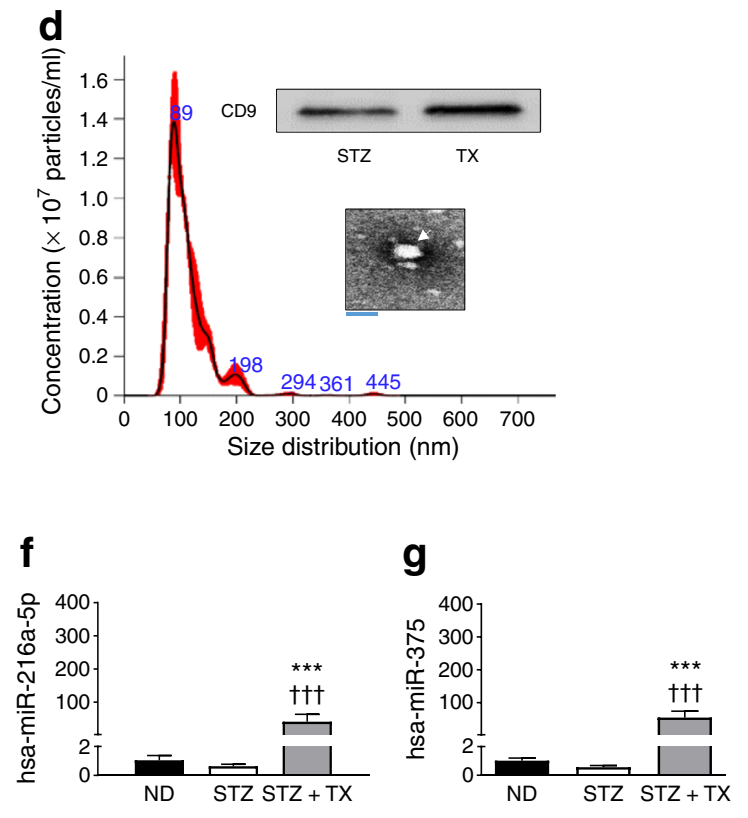

i

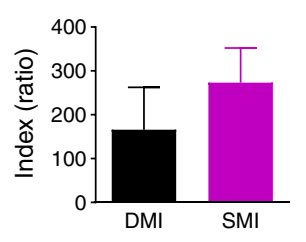

Plasma levels of these S-miRs (miR-29b-3p and miR-216a$5 p$ ) and D-miRs (miR-375 and miR-148a-3p) were increased in STZ diabetic nude mice transplanted with isolated human islets under the kidney capsule or intraportally. These human exo-miRNAs were not detected in control STZ diabetic nude mice. Other exo-miRNAs were not detectible in these transplant models except for hsa-miR-200c-3p (fold change 2.95) and hsa-miR-92a-3p (fold change 23.8) in a kidney capsule transplant model, consistent with our previous clinical results
[12]. These results clearly suggest that elevated plasma S-miRs and D-miRs correspond to islet stress and damage immediately post transplantation due to inflammation and hypoxia. Islet stress was evident from increased expression of NOS2, HIF1A, FOS, CXCL10, IL6 and TNF in islet grafts at $24 \mathrm{~h}$ post transplantation (ESM Fig. 4). We calculated stress and damage indices (SMI and DMI) using a stable exo-miRNA, hsa-miR889, expression of which did not change after cytokine or hypoxia treatment ex vivo (Figs. 4, 5). SMI and DMI were both
Table 2 TPIAT patient information

\begin{tabular}{llllll}
\hline Patient no. & $\begin{array}{l}\text { Transplanted } \\
\text { pellet volume }(\mathrm{ml})\end{array}$ & No. of bags & Islet dose (IEQ) & $\begin{array}{l}\text { IEQ/kg } \\
\text { body weight }\end{array}$ & $\begin{array}{l}\text { Incubation time } \\
\text { before infusion (h) }\end{array}$ \\
\hline TPIAT 1 & 27 & 3 & 760334 & 7558 & 1 \\
TPIAT 2 & 16 & 2 & 486580 & 5106 & 1 \\
TPIAT 3 & 26 & 3 & 375607 & 6137 & 1 \\
TPIAT 4 & 13 & 2 & 353000 & 4095 & 1 \\
TPIAT 5 & 15 & 2 & 440584 & 5700 & 1 \\
TPIAT 6 & 26 & 3 & 419540 & 5406 & 1 \\
\hline
\end{tabular}


Fig. 5 Exo-miRNA profile during and post TPIAT. (a) Time course of change (plotted on a logarithmic scale) in release of SmiR and D-miR miRNAs during (Pre [1 h before islet infusion], Mid [middle of islet infusion] and End [completion of islet infusion]) and post TPIAT (6 h, 1 day and 7 days post islet infusion). (b) Time course of change in release of other validated (in vitro) exo-miRNAs during and post TPIAT. (c-h) Pearson's two-tailed correlation plots of DMI and SMI with SUITO index, C-peptide (mmol/l) and $\mathrm{HbA}_{1 \mathrm{c}}(\mathrm{mmol} / \mathrm{mol})$ at 1 year post TPIAT. S-miRs and D-miRs were normalised to hsa-miR-8893 p, a stable exo-miRNA control, and are shown as fold change relative to the Pre islet infusion time point. Data are presented as mean \pm SEM ( $n=6$ individuals). One-way ANOVA followed by Tukey's multiple comparison test was performed for analysing time course changes in exo-miRNAs during and post TPIAT $(\mathbf{a}, \mathbf{b})$. *** $p<0.001$ compared with Pre islet infusion time
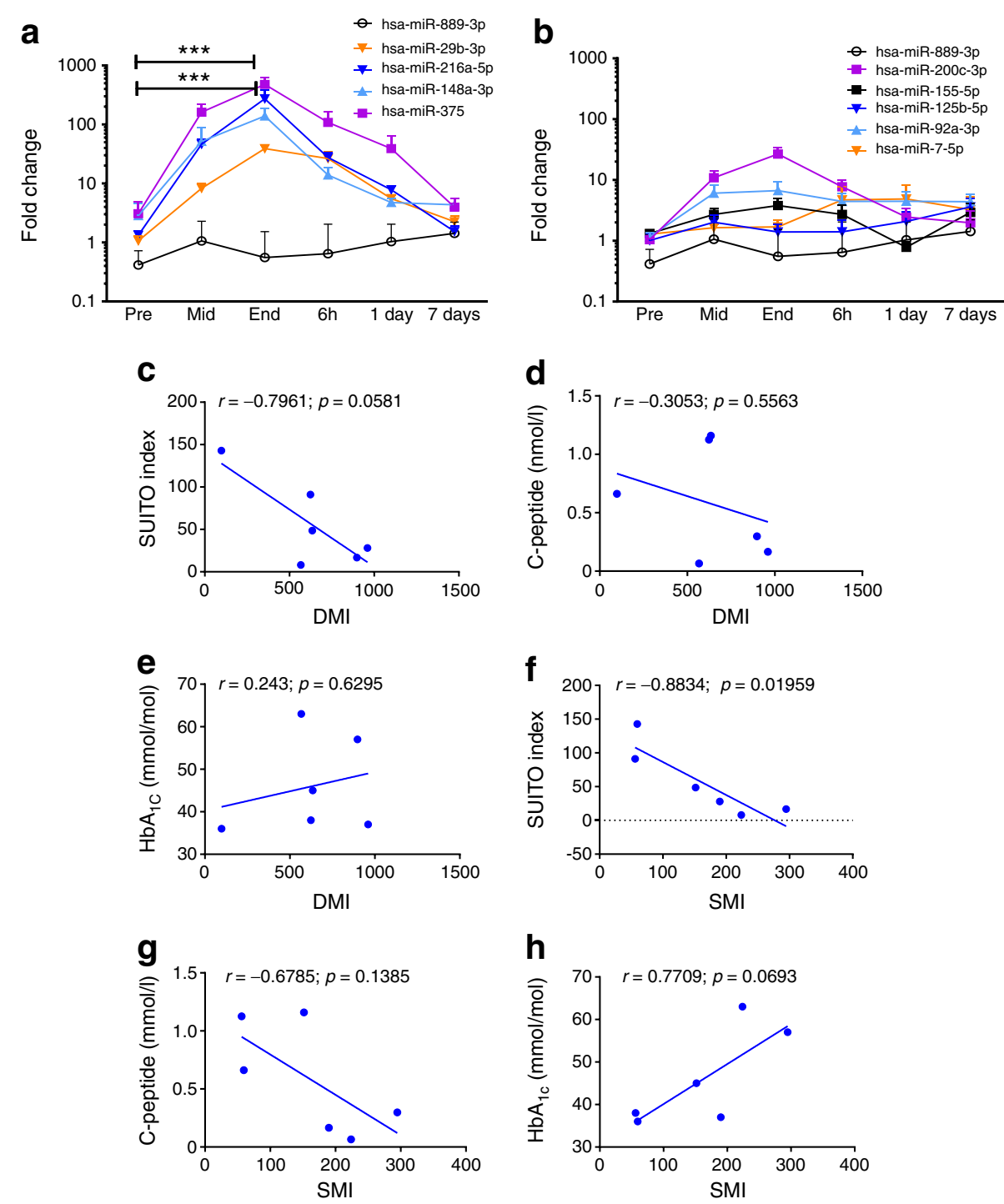

increased considerably, with SMI slightly higher than DMI in the kidney capsule transplant model. Islet beta cell stress and dysfunction were also evident from reduced INS1 mRNA levels in islet grafts at $24 \mathrm{~h}$ post transplantation. In a model of human-into-mouse xenoislet transplantation, both islet graft and plasma exosomes contained miR-375 among various other miRNAs, which differed from our list of exo-miRNAs [30]. These differences could be attributed to the reference exomiRNA and controls used to analyse data. Nevertheless, both studies highlight changes in exosome cargo that can be tapped for identification of non-invasive biomarkers.

In TPIAT patients, time course analyses indicated that plasma levels of hsa-miR-375, hsa-miR-216a-5p, hsa-miR-148a$3 p$ and hsa-miR-29b-3p peaked at completion of islet infusion and normalised to pre-transplant levels after 7 days (Fig. 5). Plasma levels of hsa-miR-200c-3p and hsa-miR-92a-3p were elevated, although not significantly, compared with pretransplant levels. Our analyses suggested negative correlation between SMI (of peak exo-miRNAs) and the islet SUITO index of islet graft function [48] $\left(r^{2}=-0.8834 ; p=0.020\right)$ and Cpeptide $\left(r^{2}=-0.6785 ; p=0.139\right)$ and a positive correlation between SMI and $\mathrm{HbA}_{1 \mathrm{c}}(\%)\left(r^{2}=0.7709 ; p=0.069\right)$. DMI correlated negatively with SUITO index $\left(r^{2}=-0.7961\right.$; $p=0.058$ ) but not C-peptide or $\mathrm{HbA}_{1 \mathrm{c}}$. SUITO index is a valuable tool with which to predict post-transplant insulin independence and islet engraftment [48]. We previously demonstrated that hsa-miR-375 and hsa-miR-200c are reliable biomarkers of islet cell damage and predictors of post-transplant graft function in TPIAT patients $[12,13]$. S-miRs provide an opportunity to monitor islet stress and intervene during the transplantation procedure to preserve islet function/survival and enhance efficiency to achieve long-term insulin independence.

We identified the targets of these exo-miRNAs in islets using in silico KEGG analyses and the MirTrap system. hsamiR-29b-3p, hsa-miR-216a-5p, hsa-miR-375 and hsa-miR148a-3p targeted mRNAs mainly in PI3K-Akt signalling 
Table 3 KEGG analysis to predict the mRNA targets of hsa-miR-216a5p, hsa-miR-29b-3p, hsa-miR-375 and hsa-miR-148a-3p

\begin{tabular}{lll}
\hline KEGG pathway & $p$ value & No. of genes \\
\hline PI3K-Akt signalling pathway & $5.03 \times 10^{-5}$ & 63 \\
Focal adhesion & $1.36 \times 10^{-5}$ & 47 \\
FOXO signalling pathway & 0.0005 & 30 \\
Proteoglycans in cancer & 0.02 & 30 \\
Protein digestion and absorption & $1.36 \times 10^{-5}$ & 27 \\
Amoebiasis & $3.72 \times 10^{-9}$ & 26 \\
Extracellular matrix-receptor interaction & $1.38 \times 10^{-73}$ & 24 \\
Platelet activation & 0.015 & 24 \\
Thyroid hormone signalling pathway & $5.03 \times 10^{-5}$ & 22 \\
Choline metabolism in cancer & 0.014 & 21 \\
Small-cell lung cancer & 0.01 & 20 \\
Prostate cancer & 0.04 & 18 \\
Glioma & 0.0004 & 15 \\
Renal cell carcinoma & 0.004 & 15 \\
mTOR signalling pathway & 0.02 & 15 \\
Non-small-cell lung cancer & 0.03 & 13 \\
Lysine degradation & $9.54 \times 10^{-5}$ & 10 \\
Prion diseases & $8.91 \times 10^{-21}$ & 5 \\
Biotin metabolism & $5.40 \times 10^{-5}$ & 1 \\
\hline
\end{tabular}

pathway. The significance of the PI3K-Akt signalling pathway in regulation of beta cell function/survival is well established $[49,50]$. We identified 21 mRNAs in the PI3KAkt signalling pathway as targets of hsa-miR-29b-3p and hsamiR-216a-5p using MirTrap-PCR array studies. In addition to PI3K-Akt signalling, these miRNAs targeted myeloid differentiation primary response gene 88 (MyD88), NF- $\mathrm{KB} 1$ and BCL2-associated death promoter (BAD). MyD88 plays a crucial role in NF- $\mathrm{KB}$ activation and eventually islet dysfunction after clinical islet transplantation [51] and in the progression of type 1 diabetes [52]. Deregulated PI3KAkt-IRS1 signalling is a hallmark event in beta cell dysfunction in diabetes [53, 54]. PI3K-Akt signalling regulates activity of $\mathrm{BAD}$, a pro-apoptotic protein, during conditions of islet stress $[55,56]$. We hypothesise that stress situations induce miRNAs that preserve beta cell function/ survival extracellularly in exosomes, in addition to inducing stress response and apoptosis pathways. Exosomes contain various molecules that communicate with other organ systems, possibly to induce damage/repair response to maintain homeostasis. Interestingly, beta cell-specific

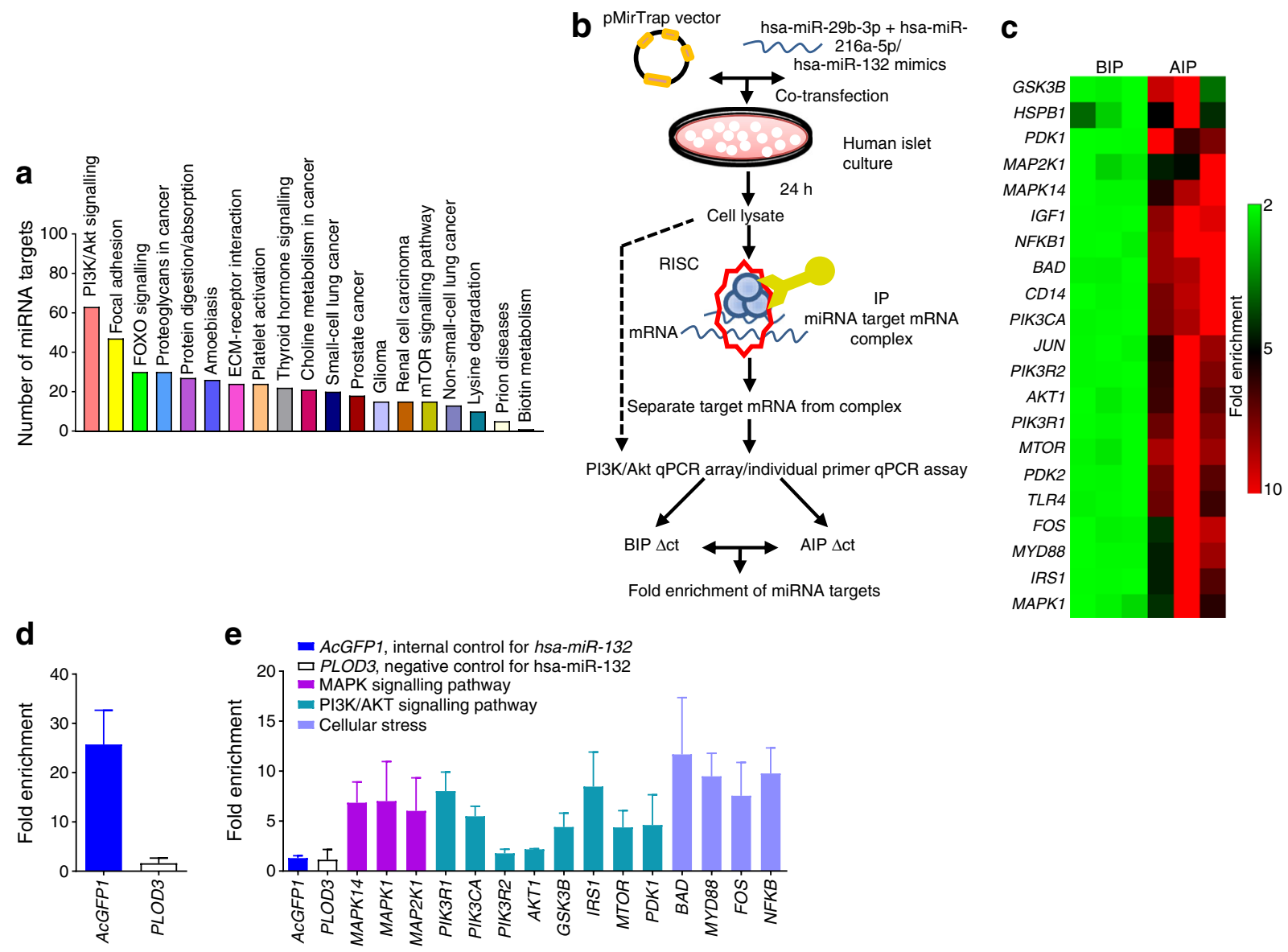

Fig. 6 Exo-miRNA target analyses using the MirTrap system (hsa-miR29b-3p; hsa-miR-216a-5p). (a) KEGG pathway prediction for hsa-miR29b-3p, hsa-miR-216a-5p, hsa-miR-375 and hsa-miR-148a-3p. (b) Design of the MirTrap system. (c) Heat map representing fold enrichment before

and after immunoprecipitation (BIP/AIP) using the $\mathrm{RT}^{2}$ profiler PCR array system. (d, e) Fold enrichment of select mRNAs using qPCR. Data are presented as mean \pm SEM ( $n=3$ samples). IP, immunoprecipitate; MAPK, mitogen-activated protein kinase; RISC, RNA-induced silencing complex 
Table 4 Genes significantly enriched after immunoprecipitation and PI3K-Akt signalling pathway array after MirTrap

\begin{tabular}{|c|c|c|c|c|c|c|}
\hline \multirow[t]{2}{*}{ Gene } & \multicolumn{2}{|c|}{ Average count } & \multicolumn{2}{|l|}{ SD } & \multirow[t]{2}{*}{$p$ value } & \multirow{2}{*}{$\begin{array}{l}\text { Fold } \\
\text { enrichmen }\end{array}$} \\
\hline & BIP & AIP & $\mathrm{BIP}$ & AIP & & \\
\hline$A K T 1$ & 34.13 & 37.22 & 0.50 & 0.15 & 0.05 & 7.89 \\
\hline$B A D$ & 34.75 & 37.86 & 0.34 & 0.29 & 0.0001 & 14.50 \\
\hline$C D 14$ & 35.83 & 37.55 & 0.52 & 0.25 & 0.0005 & 9.49 \\
\hline FOS & 34.10 & 36.21 & 0.79 & 0.33 & 0.04 & 7.10 \\
\hline GSK3B & 33.22 & 37.70 & 0.18 & 0.79 & 0.03 & 5.64 \\
\hline HSPB 1 & 31.49 & 37.48 & 0.38 & 0.25 & 0.03 & 4.98 \\
\hline$I G F 1$ & 36.29 & 37.22 & 0.27 & 0 & 0.0009 & 9.55 \\
\hline IRS1 & 35.61 & 36.17 & 1.25 & 0.80 & 0.04 & 10.60 \\
\hline$J U N$ & 34.18 & 38.22 & 0.09 & 0 & 0.006 & 3.21 \\
\hline$M A P 2 K 1$ & 33.13 & 37.07 & 0.73 & 0.66 & 0.03 & 7.14 \\
\hline$M A P K 1$ & 33.32 & 36.89 & 1.74 & 0.64 & 0.03 & 8.46 \\
\hline MAPK14 & 34.62 & 36.45 & 1.06 & 1.07 & 0.04 & 8.82 \\
\hline MTOR & 33.19 & 37.22 & 0.30 & 0 & 0.005 & 4.12 \\
\hline MYD 88 & 34.59 & 35.93 & 0.68 & 0.67 & 0.03 & 12.39 \\
\hline$N F K B 1$ & 34.17 & 37.66 & 0.54 & 0 & 0.002 & 4.41 \\
\hline$P D K 1$ & 34.57 & 36.11 & 0.18 & 0.71 & 0.04 & 5.37 \\
\hline$P D K 2$ & 31.12 & 35.24 & 0.10 & 0.15 & 0.001 & 7.23 \\
\hline PIK $3 C A$ & 34.10 & 37.89 & 0.14 & 0 & 0.008 & 6.10 \\
\hline PIK3R1 & 35.20 & 36.12 & 0.72 & 0 & 0.004 & 4.51 \\
\hline PIK3R2 & 35.74 & 36.00 & 1.01 & 0 & 0.002 & 6.54 \\
\hline$T L R 4$ & 35.30 & 38.25 & 0.28 & 0 & 0.002 & 4.81 \\
\hline
\end{tabular}

AIP, after immunoprecipitation; BIP, before immunoprecipitation

exosomes containing miR-29b-3p exerted immunoregulatory effects through TNF- $\alpha$, IL- 6 and IL-10 cytokine secretion from splenocytes isolated from diabetes-prone NOD mice ex vivo [57]. Further investigations are warranted to understand how stress conditions direct islet miRNAs to exosomes instead of vital biological processes.

Our extensive investigations reported here provide proof of concept, for the first time, that exo-miRNAs in circulation can be utilised for their ability to predict islet beta cell stress even before onset of beta cell failure in the context of prediabetes and islet auto-transplantation. Our reproducible observations, reported here and previously, clearly establish hsa-miR-375 as a beta cell damage marker. While biomarkers of beta cell damage are useful in predicting future insulin dependence, biomarkers of beta cell stress early in the pathological events leading to failure are necessary tools in halting progression of dysfunction. A consistent increase in hsa-miR-29b-3p and hsa-miR-216a-5p as early as $6 \mathrm{~h}$ after CC + HYP exposure provides valuable information on the state of beta cell stress. Hormones, hormone mimetics and pharmacological therapies that target beta cell stress and function can be used effectively during states of beta cell stress even before onset of clinical symptoms. These investigations are valuable especially to our clinic and others during the TPIAT procedure to optimise islet preservation strategies and achieve successful engraftment. Overall, we report two S-miRs, hsa-miR-29b-3p and hsamiR-216a-5p, with great potential as biomarkers of islet cell stress.

Acknowledgements Technical support by Y. Liu and A. Rahman, Islet Cell Laboratory, Baylor Simmons Transplant Institute, is acknowledged.

Data availability All data are archived in Institutional Network Drive and are available upon request from the corresponding authors. miRNA-seq data will be uploaded to Gene Expression Omnibus and available once the data are published.

Funding The study was supported by an institutional grant from Baylor University Medical Center.

Duality of interest The authors declare that there is no duality of interest associated with this manuscript.

Contribution statement PBS designed the study, performed experiments, analysed data and wrote the manuscript. SV analysed data and wrote and revised the manuscript. GY and CMD assisted in performing in vivo experiments, data analysis and manuscript preparation. XW and JG analysed microRNA sequencing data and assisted in manuscript preparation. MCL and BN designed and supervised the study, analysed data and wrote the manuscript. All authors approve the final version of the manuscript. BN is responsible for the integrity of the work as a whole.

\section{References}

1. Donath MY, Boni-Schnetzler M, Ellingsgaard H, Halban PA, Ehses JA (2010) Cytokine production by islets in health and diabetes: cellular origin, regulation and function. Trends Endocrinol Metab 21(5):261-267. https://doi.org/10.1016/j.tem.2009.12.010

2. Maedler K, Sergeev P, Ris F et al (2002) Glucose-induced $\beta$ cell production of IL-1 $\beta$ contributes to glucotoxicity in human pancreatic islets. J Clin Invest 110(6):851-860. https://doi.org/10.1172/ jci15318

3. Vivot K, Langlois A, Bietiger W et al (2014) Pro-inflammatory and pro-oxidant status of pancreatic islet in vitro is controlled by TLR-4 and HO-1 pathways. PLoS One 9(10):e107656. https://doi.org/10. 1371/journal.pone.0107656

4. SoRelle JA, Itoh T, Peng H et al (2013) Withaferin A inhibits proinflammatory cytokine-induced damage to islets in culture and following transplantation. Diabetologia 56(4):814-824. https://doi. org/10.1007/s00125-012-2813-9

5. Yoshimatsu G, Kunnathodi F, Saravanan PB et al (2017) Pancreatic $\beta$-cell-derived IP-10/CXCL10 isletokine mediates early loss of graft function in islet cell transplantation. Diabetes 66(11):28572867. https://doi.org/10.2337/db17-0578

6. Piemonti L, Leone BE, Nano R et al (2002) Human pancreatic islets produce and secrete MCP-1/CCL2: relevance in human islet transplantation. Diabetes 51(1):55-65. https://doi.org/10.2337/diabetes. 51.1.55

7. Belgardt BF, Ahmed K, Spranger M et al (2015) The microRNA200 family regulates pancreatic beta cell survival in type 2 diabetes. Nat Med 21(6):619-627. https://doi.org/10.1038/nm.3862

8. El Ouaamari A, Baroukh N, Martens GA, Lebrun P, Pipeleers D, van Obberghen E (2008) miR-375 targets 3'-phosphoinositide-dependent protein kinase-1 and regulates glucose-induced biological 
responses in pancreatic $\beta$-cells. Diabetes 57(10):2708-2717. https://doi.org/10.2337/db07-1614

9. LaPierre MP, Stoffel M (2017) MicroRNAs as stress regulators in pancreatic beta cells and diabetes. Mol Metab 6(9):1010-1023. https://doi.org/10.1016/j.molmet.2017.06.020

10. Poy MN, Eliasson L, Krutzfeldt J et al (2004) A pancreatic isletspecific microRNA regulates insulin secretion. Nature 432(7014): 226-230. https://doi.org/10.1038/nature03076

11. van de Bunt M, Gaulton KJ, Parts L et al (2013) The miRNA profile of human pancreatic islets and beta-cells and relationship to type 2 diabetes pathogenesis. PLoS One 8(1):e55272. https://doi.org/10. 1371/journal.pone.0055272

12. Saravanan PB, Kanak MA, Chang CA et al (2018) Islet damage during isolation as assessed by miRNAs and the correlation of miRNA levels with posttransplantation outcome in islet autotransplantation. Am J Transplant 18(4):982-989. https://doi. org/10.1111/ajt.14615

13. Yoshimatsu G, Takita M, Kanak MA et al (2016) MiR-375 and miR-200c as predictive biomarkers of islet isolation and transplantation in total pancreatectomy with islet autotransplantation. J Hepatobiliary Pancreat Sci 23(9):585-594. https://doi.org/10. 1002/jhbp.377

14. Kanak MA, Takita M, Shahbazov R et al (2015) Evaluation of microRNA375 as a novel biomarker for graft damage in clinical islet transplantation. Transplantation 99(8):1568-1573. https://doi. org/10.1097/tp.0000000000000625

15. Biarnes M, Montolio M, Nacher V, Raurell M, Soler J, Montanya E (2002) $\beta$-Cell death and mass in syngeneically transplanted islets exposed to short- and long-term hyperglycemia. Diabetes 51(1):6672. https://doi.org/10.2337/diabetes.51.1.66

16. Coronel MM, Geusz R, Stabler CL (2017) Mitigating hypoxic stress on pancreatic islets via in situ oxygen generating biomaterial. Biomaterials 129:139-151. https://doi.org/10.1016/j.biomaterials. 2017.03.018

17. Davalli AM, Scaglia L, Zangen DH, Hollister J, Bonner-Weir S, Weir GC (1996) Vulnerability of islets in the immediate posttransplantation period. Dynamic changes in structure and function. Diabetes 45(9):1161-1167. https://doi.org/10.2337/diab.45.9.1161

18. Kanak MA, Takita M, Kunnathodi F, Lawrence MC, Levy MF, Naziruddin B (2014) Inflammatory response in islet transplantation. Int J Endocrinol 2014:451035. https://doi.org/10.1155/2014/ 451035

19. Nayak DK, Saravanan PB, Bansal S, Naziruddin B, Mohanakumar $\mathrm{T}$ (2016) Autologous and allogenous antibodies in lung and islet cell transplantation. Front Immunol 7:650. https://doi.org/10.3389/ fimmu.2016.00650

20. Shahbazov R, Kanak MA, Takita M et al (2016) Essential phospholipids prevent islet damage induced by proinflammatory cytokines and hypoxic conditions. Diabetes Metab Res Rev 32(3):268-277. https://doi.org/10.1002/dmrr.2714

21. Naziruddin B, Iwahashi S, Kanak MA, Takita M, Itoh T, Levy MF (2014) Evidence for instant blood-mediated inflammatory reaction in clinical autologous islet transplantation. Am J Transplant 14(2): 428-437. https://doi.org/10.1111/ajt.12558

22. Olsson R, Olerud J, Pettersson U, Carlsson PO (2011) Increased numbers of low-oxygenated pancreatic islets after intraportal islet transplantation. Diabetes 60(9):2350-2353. https://doi.org/10. 2337/db09-0490

23. Omori K, Kobayashi E, Rawson J, Takahashi M, Mullen Y (2016) Mechanisms of islet damage mediated by pancreas cold ischemia/ rewarming. Cryobiology 73(2):126-134. https://doi.org/10.1016/j. cryobiol.2016.08.010

24. Barutta F, Tricarico M, Corbelli A et al (2013) Urinary exosomal microRNAs in incipient diabetic nephropathy. PLoS One 8(11): e73798. https://doi.org/10.1371/journal.pone.0073798
25. Bijkerk R, Duijs JM, Khairoun M et al (2015) Circulating microRNAs associate with diabetic nephropathy and systemic microvascular damage and normalize after simultaneous pancreaskidney transplantation. Am J Transplant 15(4):1081-1090. https://doi.org/10.1111/ajt.13072

26. Guay C, Regazzi R (2013) Circulating microRNAs as novel biomarkers for diabetes mellitus. Nat Rev Endocrinol 9(9):513-521. https://doi.org/10.1038/nrendo.2013.86

27. Andreu Z, Yanez-Mo M (2014) Tetraspanins in extracellular vesicle formation and function. Front Immunol 5:442. https://doi.org/10. 3389/fimmu.2014.00442

28. Cianciaruso C, Phelps EA, Pasquier M et al (2017) Primary human and rat $\beta$-cells release the intracellular autoantigens GAD65, IA-2, and proinsulin in exosomes together with cytokine-induced enhancers of immunity. Diabetes 66(2):460-473. https://doi.org/10. 2337/db16-0671

29. Lancaster GI, Febbraio MA (2005) Exosome-dependent trafficking of HSP70: a novel secretory pathway for cellular stress proteins. J Biol Chem 280(24):23349-23355. https://doi.org/10.1074/jbc. M502017200

30. Vallabhajosyula P, Korutla L, Habertheuer A et al (2017) Tissuespecific exosome biomarkers for noninvasively monitoring immunologic rejection of transplanted tissue. J Clin Invest 127(4):13751391. https://doi.org/10.1172/jci87993

31. Bensellam M, Maxwell EL, Chan JY et al (2016) Hypoxia reduces ER-to-Golgi protein trafficking and increases cell death by inhibiting the adaptive unfolded protein response in mouse beta cells. Diabetologia 59(7):1492-1502. https://doi.org/10.1007/ s00125-016-3947-y

32. Emamaullee J, Liston P, Korneluk RG, Shapiro AM, Elliott JF (2005) XIAP overexpression in islet $\beta$-cells enhances engraftment and minimizes hypoxia-reperfusion injury. Am J Transplant 5(6): 1297-1305. https://doi.org/10.1111/j.1600-6143.2005.00891.x

33. Emamaullee JA, Rajotte RV, Liston P et al (2005) XIAP overexpression in human islets prevents early posttransplant apoptosis and reduces the islet mass needed to treat diabetes. Diabetes 54(9): 2541-2548. https://doi.org/10.2337/diabetes.54.9.2541

34. Hayes HL, Peterson BS, Haldeman JM, Newgard CB, Hohmeier HE, Stephens SB (2017) Delayed apoptosis allows islet beta-cells to implement an autophagic mechanism to promote cell survival. PLoS One 12(2):e0172567. https://doi.org/10.1371/journal.pone. 0172567

35. Laybutt DR, Preston AM, Akerfeldt MC et al (2007) Endoplasmic reticulum stress contributes to beta cell apoptosis in type 2 diabetes. Diabetologia 50(4):752-763. https://doi.org/10.1007/s00125-0060590-Z

36. Yang YH, Johnson JD (2013) Multi-parameter single-cell kinetic analysis reveals multiple modes of cell death in primary pancreatic $\beta$-cells. J Cell Sci 126(Pt 18):4286-4295. https://doi.org/10.1242/ jcs. 133017

37. Allagnat F, Fukaya M, Nogueira TC et al (2012) C/EBP homologous protein contributes to cytokine-induced pro-inflammatory responses and apoptosis in $\beta$-cells. Cell Death Differ 19(11):18361846. https://doi.org/10.1038/cdd.2012.67

38. Calfon M, Zeng H, Urano F et al (2002) IRE1 couples endoplasmic reticulum load to secretory capacity by processing the XBP-1 mRNA. Nature 415(6867):92-96. https://doi.org/10.1038/415092a

39. Bagge A, Clausen TR, Larsen S et al (2012) MicroRNA-29a is upregulated in beta-cells by glucose and decreases glucose-stimulated insulin secretion. Biochem Biophys Res Commun 426(2):266-272. https://doi.org/10.1016/j.bbrc.2012.08.082

40. Esguerra JL, Bolmeson C, Cilio CM, Eliasson L (2011) Differential glucose-regulation of microRNAs in pancreatic islets of non-obese type 2 diabetes model Goto-Kakizaki rat. PLoS One 6(4):e18613. https://doi.org/10.1371/journal.pone.0018613 
41. Guay C, Jacovetti C, Nesca V, Motterle A, Tugay K, Regazzi R (2012) Emerging roles of non-coding RNAs in pancreatic $\beta$-cell function and dysfunction. Diabetes Obes Metab 14(Suppl 3):1221. https://doi.org/10.1111/j.1463-1326.2012.01654.x

42. Rodriguez-Comas J, Moreno-Asso A, Moreno-Vedia J et al (2017) Stress-induced microRNA-708 impairs $\beta$-cell function and growth. Diabetes 66(12):3029-3040. https://doi.org/10.2337/db16-1569

43. Bravo-Egana V, Rosero S, Klein D et al (2012) Inflammationmediated regulation of microRNA expression in transplanted pancreatic islets. J Transp Secur 2012:723614-723615. https://doi.org/ $10.1155 / 2012 / 723614$

44. Guay C, Regazzi R (2015) Role of islet microRNAs in diabetes: which model for which question? Diabetologia 58(3):456-463. https://doi.org/10.1007/s00125-014-3471-x

45. Jacovetti C, Matkovich SJ, Rodriguez-Trejo A, Guay C, Regazzi R (2015) Postnatal beta-cell maturation is associated with isletspecific microRNA changes induced by nutrient shifts at weaning. Nat Commun 6:8084. https://doi.org/10.1038/ncomms9084

46. Klein D, Misawa R, Bravo-Egana V et al (2013) MicroRNA expression in alpha and beta cells of human pancreatic islets. PLoS One 8(1):e55064. https://doi.org/10.1371/journal.pone.0055064

47. Setyowati Karolina D, Sepramaniam S, Tan HZ, Armugam A, Jeyaseelan K (2013) miR-25 and miR-92a regulate insulin I biosynthesis in rats. RNA Biol 10(8):1365-1378. https://doi.org/10. 4161/rna.25557

48. Takita M, Matusmoto S (2012) SUITO index for evaluation of clinical islet transplantation. Cell Transplant 21(7):1341-1347. https://doi.org/10.3727/096368912x636885

49. Eto K, Yamashita T, Tsubamoto Y et al (2002) Phosphatidylinositol 3-kinase suppresses glucose-stimulated insulin secretion by affecting post-cytosolic $[\mathrm{Ca}(2+)]$ elevation signals. Diabetes 51(1):8797. https://doi.org/10.2337/diabetes.51.1.87

50. Tuo Y, Xiang M (2018) mTOR: a double-edged sword for diabetes. J Leukoc Biol. https://doi.org/10.1002/jlb.3mr0317-095rr
51. Chang CA, Akinbobuyi B, Quintana JM, Yoshimatsu G, Naziruddin B, Kane RR (2018) Ex-vivo generation of drugeluting islets improves transplant outcomes by inhibiting TLR4mediated NFkB upregulation. Biomaterials 159:13-24. https:// doi.org/10.1016/j.biomaterials.2017.12.020

52. Burrows MP, Volchkov P, Kobayashi KS, Chervonsky AV (2015) Microbiota regulates type 1 diabetes through Toll-like receptors. Proc Natl Acad Sci U S A 112(32):9973-9977. https://doi.org/10. 1073/pnas.1508740112

53. Gunton JE, Kulkarni RN, Yim S et al (2005) Loss of ARNT/HIF1 $\beta$ mediates altered gene expression and pancreatic-islet dysfunction in human type 2 diabetes. Cell 122(3):337-349. https://doi.org/10. 1016/j.cell.2005.05.027

54. Muller D, Huang GC, Amiel S, Jones PM, Persaud SJ (2006) Identification of insulin signaling elements in human $\beta$-cells: autocrine regulation of insulin gene expression. Diabetes 55(10):28352842. https://doi.org/10.2337/db06-0532

55. Federici M, Hribal ML, Ranalli M et al (2001) The common Arg972 polymorphism in insulin receptor substrate-1 causes apoptosis of human pancreatic islets. FASEB J 15(1):22-24. https:// doi.org/10.1096/fj.00-0414fje

56. Nishihama K, Yasuma T, Yano Y et al (2018) Anti-apoptotic activity of human matrix metalloproteinase-2 attenuates diabetes mellitus. Metabolism 82:88-99. https://doi.org/10.1016/j.metabol. 2018.01.016

57. Salama A, Fichou N, Allard M et al (2014) MicroRNA-29b modulates innate and antigen-specific immune responses in mouse models of autoimmunity. PLoS One 9(9):e106153. https://doi.org/ 10.1371/journal.pone.0106153

Publisher's note Springer Nature remains neutral with regard to jurisdictional claims in published maps and institutional affiliations. 